\title{
Peripherally acting $\mu$-opioid receptor antagonists as treatment options for constipation in noncancer pain patients on chronic opioid therapy
}

This article was published in the following Dove Press journal:

Patient Preference and Adherence

17 January 2017

Number of times this article has been viewed

\author{
Joseph V Pergolizzi Jr \\ Robert B Raffa ${ }^{2,3}$ \\ Marco Pappagallo 4 \\ Charles Fleischer ${ }^{1}$ \\ Joseph Pergolizzi III' \\ Gianpietro Zampogna ${ }^{5}$ \\ Elizabeth Duval' \\ Janan Hishmeh' \\ Jo Ann LeQuang' \\ Robert Taylor Jr' \\ 'NEMA Research, Inc., Naples, FL, \\ ${ }^{2}$ University of Arizona College of \\ Pharmacy, University of Arizona, \\ Tucson, AZ, ${ }^{3}$ Temple University School \\ of Pharmacy, Temple University, \\ Philadelphia, PA, ${ }^{4}$ Department of \\ Medicine, Albert Einstein College of \\ Medicine, New York, NY, ${ }^{5}$ Department \\ of Medicine, St. Luke's Hospital, \\ Cleveland, OH, USA
}

Correspondence: Joseph V Pergolizzi Jr NEMA Research, Inc., 868-106 Avenue N, Naples, FL 34108, USA

$\mathrm{Tel}+\mathrm{I} 2395973564$

Email jpjmd@msn.com

\begin{abstract}
Opioid-induced constipation (OIC), a prevalent and distressing side effect of opioid therapy, does not reliably respond to treatment with conventional laxatives. OIC can be a treatment-limiting adverse event. Recent advances in medications with peripherally acting $\mu$-opioid receptor antagonists, such as methylnaltrexone, naloxegol, and alvimopan, hold promise for treating OIC and thus extending the benefits of opioid analgesia to more chronic pain patients. Peripherally acting $\mu$-opioid receptor antagonists have been clinically tested to improve bowel symptoms without compromise to pain relief, although there are associated side effects, including abdominal pain. Other treatment options include fixed-dose combination products of oxycodone analgesic together with naloxone.
\end{abstract}

Keywords: opioid-induced constipation, opioid bowel disorder, PAMORA, peripherally acting mu-opioid receptor antagonist, noncancer pain patients, opioid-associated side effects

\section{Introduction}

Some form of opioid bowel disorder, particularly opioid-induced constipation (OIC), affects $40 \%-90 \%$ of patients on long-term opioid therapy. ${ }^{1}$ Even with short-term use, opioid analgesic therapy can result in symptoms of constipation. The use of opioids for 5 days produced nearly twofold patient-reported symptoms of constipation in opioidtreated patients vs placebo patients $(P<0.001)$ and an objectively measured $41 \%$ segmental colorectal volume increase in the cecum and/or ascending colon $(P=0.005 \mathrm{vs}$ placebo). ${ }^{2}$ After 5 days of oxycodone therapy, the median gastrointestinal (GI) transit time increased from 22.2 hours to 43.9 hours $(P<0.001){ }^{3}$ Thus, the short- as well as long-term use of opioids can result in bowel-related symptoms, most notably OIC. OIC does not reliably respond to treatment with conventional laxatives. ${ }^{4} \mathrm{With}$ growing numbers of patients prescribed opioid analgesics to address pain as the "fifth vital sign" ${ }^{\circ}$ and pain relief viewed as a fundamental human right, ${ }^{6}$ the total number of patients with OIC has rapidly increased. ${ }^{7}$

The burden of OIC includes patient distress and discomfort, increased physician visits, absences from work and reduced productivity, and an impaired quality of life compared with similar opioid-treated patients who do not have OIC. ${ }^{8}$ OIC can limit opioid therapy and may adversely impact patient adherence, adequate pain control, and patient function and in rare case even causes stercoral perforation, a potentially fatal complication. ${ }^{9} 10$ Treatment options for OIC have typically included a bowel regimen with lifestyle modifications and nonpharmacological strategies to be supplemented with conventional laxatives. A new class of agents addresses OIC that does not 
respond to lifestyle changes and, further, may be refractory to conventional laxatives. These peripherally acting $\mu$-opioid receptor (MOR) antagonists (PAMORAs) represent an important advancement in the treatment of OIC. ${ }^{4}$

\section{OIC mechanisms}

The several effects that endogenous opioids (endorphins, enkephalins, etc) and exogenous opioids (analgesic agents such as morphine and oxycodone) have on various physiological processes of the GI tract have been extensively studied in animal models and humans. ${ }^{9}$ In short, opioids cause inhibition of GI emptying by delaying GI transit, stimulating nonpropulsive motor activity, increasing intestinal tone, increasing fluid absorption by prolonging contact time, and decreasing the secretion of electrolytes and water into the intestinal lumen. ${ }^{10}$ Pancreatic, biliary, and intestinal secretions are depressed by opioid administration. The combined inhibition of intestinal fluid secretion and the enhancement of absorption contribute to the constipating effect of opioids.

At the tissue level, opioids exert effects on the smooth muscle located along the GI tract. These effects arise from opioid-mediated actions both on nerves intrinsic to the gut ("intrinsic innervation") and on the nerves that innervate the gut from the brainstem and the spinal cord ("extrinsic innervation", Figure 1). The overall result is constipation. The constipation that develops from long-term use of opioid analgesics can be intolerable to patients, to the point that it can even prompt discontinuation of the use of opioids at the expense of adequate analgesic efficacy, that is, OIC can be treatment limiting.

At the molecular level, opioids act at opioid receptors that are located within the intrinsic neuronal network along the GI tract. This action inhibits gut motility. Endogenous opioids have been identified in myenteric neurons, and opioid receptors are localized at presynaptic and postsynaptic sites of the enteric neuronal (the myenteric and submucosal) plexus. In the GI tract, MORs are widely distributed in the submucosa ${ }^{11}$ as well as in the ileal mucosa, where they influence ion transport changes. ${ }^{12}$ Stomach and proximal colon have the densest concentration of 7-transmembrane $\mathrm{G}$ protein-coupled $\mu$ - and $\kappa$-opioid receptors. ${ }^{13}$ By an agonist action at these sites, opioids inhibit the firing of secretomotor and submucosal neurons. They also inhibit the release of vesicular-stored presynaptic neurotransmitters from these neurons. The effects are localized to the GI tract, ie, peripheral action. Opioids also produce inhibitory effects on the GI tract by acting on opioid receptors located in the brain and spinal cord, ie, central action. Opioids inhibit the effects of the

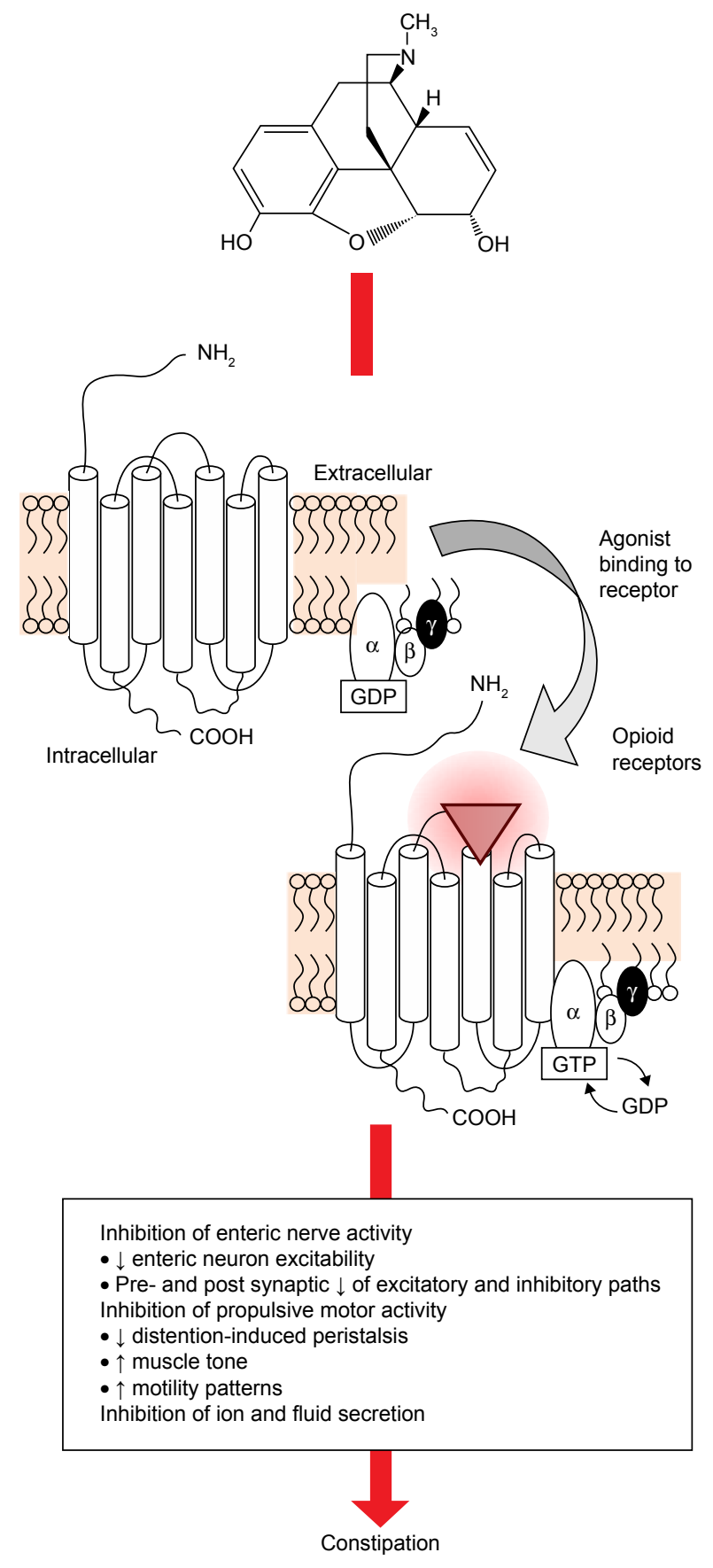

Figure I Opioid-mediated mechanism of constipation.

Abbreviations: GDP, guanosine-5'-diphosphate; GTP, guanosine-5'-triphosphate.

autonomic nervous system - parasympathetic subdivision - on GI smooth muscle and, thereby, decrease propulsive motility along the GI tracts. ${ }^{14}$ Opioids further suppress GI motility by increasing autonomic nervous system sympathetic activity, which is mediated by enhanced release of vesicular-stored norepinephrine (noradrenaline) that subsequently acts on presynaptic $\alpha 2$-adrenoceptors located on enteric neurons. ${ }^{14}$

Morphine and other opioid receptor agonist analgesics delay gastric emptying. In addition, gastric, pancreatic, 
biliary, and intestinal secretions are usually depressed by opioid administration. The combined inhibition of intestinal fluid secretion and the enhancement of absorption contribute to the production of constipation by opioid analgesics.

\section{OIC diagnosis}

Despite the widespread use of opioid analgesics, OIC may not be routinely diagnosed. ${ }^{15}$ In part, this is due to the fact that there is no recognized diagnostic criterion for OIC. ${ }^{16}$ Even a definition of OIC seems elusive. In a systematic review of OIC studies ( $n=1,488$ studies), only $34 \%$ of trials provided a clear definition of OIC, but the definitions were not consistent across studies. ${ }^{17}$ The Rome II criteria for general constipation require at least two of the following symptoms for $\geq 12$ weeks over the period of a year: straining to defecate, hard stools, sensation of incomplete evacuation or sensation of anorectal obstruction with more than one quarter of defecations, and three or fewer bowel movements per week. ${ }^{18}$ The recently published Rome IV criteria have added OIC as "disorders of the gut-brain interaction being characterized by altered function of the central nervous system or enteric nervous system" and consider them separate disorders. ${ }^{19}$ This definition is not helpful for OIC, which may commence abruptly upon onset of opioid administration and thus should be treated promptly.

A diagnosis of OIC typically results when the patient reports constipation in association with the onset of opioid use. In such cases, constipation may be defined as changes in bowel habits compared with baseline, including reduced bowel movement frequency, difficulty passing bowel movements, a sensation of incomplete or unsatisfactory evacuation, and harder and/or drier stool consistency. ${ }^{16,20,21}$ Another definition holds that OIC occurs when opioid-treated patients have fewer than three spontaneous bowel movements in a week or have bowel movements with hard stools that are difficult to pass. ${ }^{22}$

Unlike some opioid-associated side effects, OIC does not diminish over time as the patient develops tolerance to other opioid side effects. ${ }^{7}$ OIC may occur with the use of any opioid or any opioid product and any duration of treatment.

Validated tools exist for measuring constipation, which include the Patient Assessment of Constipation Symptoms, the Patient Assessment of Constipation-Quality of Life, Stool Symptom Screener, Bowel Function Index, and Bowel Function Diary. The Bowel Function Index is one of the most succinct and commonly used tools; it has been validated as a reliable assessment tool for clinically significant constipation and is the only one among these tools to be validated specifically for the assessment of OIC. ${ }^{23}$

\section{OIC management}

Prescribers initiating opioid therapy may recommend a bowel regimen to help prevent or mitigate potential GI symptoms. In a retrospective study of 2010 data from the National Hospital Ambulatory Medical Care Survey (NHAMCS), $<1 \%$ of adult patients discharged from an emergency department with a prescription for opioids were given a laxative prescription $(0.5 \%, 95 \% \mathrm{CI}, 0.7 \%-1.3 \%){ }^{24}$ In the subset of emergency room patients aged 65 years or older discharged with an opioid pain reliever prescription, $1.0 \%$ received a laxative prescription at discharge $(95 \% \mathrm{CI}$, $0.5 \%-2.0 \%) .{ }^{24}$ The authors could not find data for if and how frequently emergency departments or other patients prescribed opioids were educated about opioid-associated bowel symptoms.

Bowel regimens typically involve a nonpharmacological component of lifestyle modifications, such as increased exercise, greater fluid intake, and dietary changes. ${ }^{7,20,25}$ Such recommendations may be feasible for active noncancer pain patients, but may be unsuitable for patients with advanced illness, impaired mobility, dietary restrictions, and/or limited function. ${ }^{26}$ The pharmacological component of a bowel regimen may include stool softeners, bulking agents, osmotic agents, and stimulant-type laxatives. ${ }^{27}$ In some cases, two or more laxatives with complementary mechanisms of action may be prescribed, such as a stool softener plus a stimulant. Rectal laxatives, including stimulant suppositories such as bisacodyl, lubricants such as glycerin, and enemas are sometimes used, although care should be taken with enemas to preserve the patient's electrolyte balance. ${ }^{26}$ Figure 2 shows the proposed algorithm for the management of OIC.

Bowel regimens are not particularly effective. In an observational pilot study of 24 adult OIC patients taking oxycodone, $43 \%$ did not respond to standard laxative treatment and, if the group of patients who had developed diarrhea from the treatment were included, $75 \%$ of patients could be considered nonresponders. ${ }^{28}$ Conventional laxatives may be helpful early in the course of opioid therapy or for specific individual patients, but their efficacy in treating OIC has been limited. ${ }^{29}$ Fewer than half of OIC patients find relief with conventional laxatives. ${ }^{27}$

\section{Laxative-refractory OIC}

There is a plethora of over-the-counter and prescription laxative products, which may be grouped into four broad categories: bulking agents (psyllium and methylcellulose), nonabsorbed substances (magnesium salts), stimulants (bisacodyl and senna), and secretory drugs (lubiprostone and 


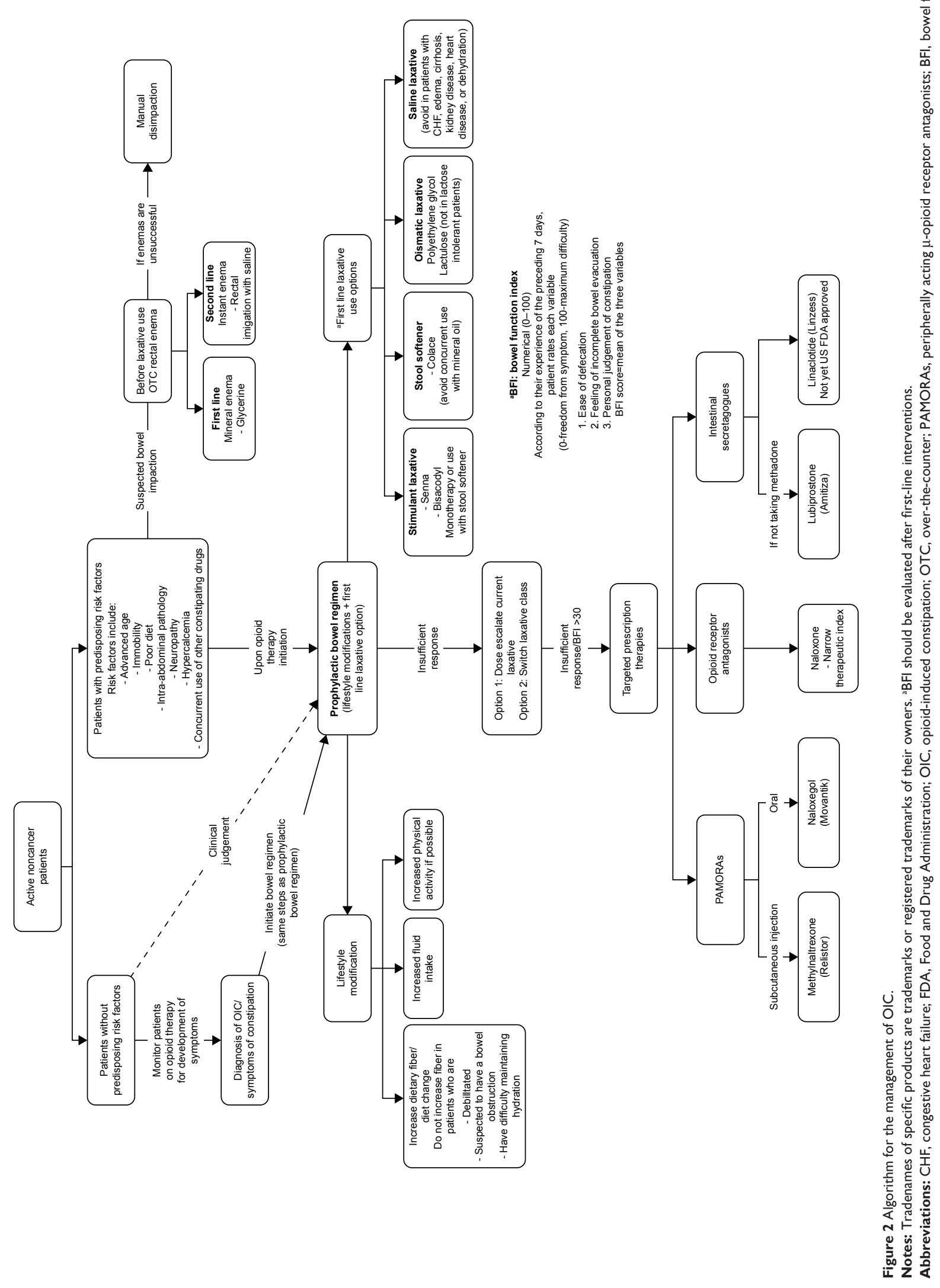


linaclotide).${ }^{10}$ Conventional laxatives may be effective when constipation is caused by dehydration, lack of fibers, or other actors, but OIC involves delayed GI transit, increased water absorption, and nonpropulsive motor activity. OIC patients prescribed laxatives do not always complain, but in a study of 489 OIC patients, of whom about half (48\%) took laxatives four or more times a week, constipation-related symptoms, quality of life assessments, and productivity levels remained roughly unchanged over the 24 weeks of the study. ${ }^{30}$ This suggests that even with frequent laxative use, OIC patients still suffer symptoms severe enough to affect their daily living. ${ }^{30}$

\section{Peripherally acting $\mu$-opioid receptor antagonists}

PAMORAs have demonstrated effectiveness in treating laxative-resistant OIC. The first PAMORA approved by the US Food and Drug Administration (FDA) for OIC in terminally ill patients was subcutaneous methylnaltrexone, which has since been approved for use in patients with chronic noncancer pain. ${ }^{31}$ Methylnaltrexone bromide (Relistor ${ }^{\mathbb{B}}$; Salix Pharmaceuticals, Inc., Raleigh, NC, USA) does not reverse the analgesic effect of opioids nor does it lead to withdrawal symptoms. A variety of PAMORA products are available today.

Alvimopan (Entereg ${ }^{\circledR}$; Merck \& Co., Inc., Whitehouse Station, NJ, USA) is an oral $\mu$-opioid receptor antagonist approved for short-term use to treat postoperative ileus in inpatients in the US. The long-term use of alvimopan is associated with cardiovascular risk. ${ }^{32}$

Naloxegol (Movantik ${ }^{\circledR}$; AstraZeneca Pharmaceuticals, LP, Wilmington, DE, USA), an oral PAMORA, is a pegylated derivative of naloxone. Naloxegol antagonizes the $\mu$-receptors of the GI tract and has been shown in in vitro studies to have a relatively low affinity for $\delta$-receptors and $\kappa$-receptors. Pegylation adds the polyethylene glycol group to this molecule; this pegylation moiety makes naloxegol less passively passable than naloxone. Furthermore, naloxegol acts as a substrate for the P-glycoprotein transporter, which increases the efflux of naloxegol across the blood-brain barrier. The increased efflux of naloxegol at the blood-brain barrier limits the extent to which naloxegol can penetrate the central nervous system. This allows naloxegol to be effective in the GI tract without reversing central analgesia via the central nervous system. ${ }^{33-35}$

\section{Other agents in treating OIC}

Lubiprostone (Amitiza; Sucampo Pharmaceuticals, Inc., Rockville, MD, USA) is an oral agent in the form of a bicyclic fatty acid that acts as a chloride channel 2 (CIC-2) activator. ${ }^{31}$ Lubiprostone activates CIC-2 in the gut, increasing intestinal fluid secretion and enhancing transit through the gut without altering sodium and potassium serum concentrations. ${ }^{36}$ In the US, lubiprostone is indicated for OIC in chronic noncancer pain patients and may also be indicated for patients with chronic idiopathic constipation. ${ }^{37,38}$

A fixed-dose combination product of oxycodone plus naloxone (Targiniq ${ }^{\circledR}$; Purdue Pharma LP, Stamford, CT, USA) allows the naloxone to negate the effects of oxycodone on the GI tract during oral administration, but the naloxone is then inactivated by hepatic metabolism so as not to impair central analgesia. ${ }^{39}$ This product may be considered a PAMORA but is considered here as another type of agent in that it relies on a drug combination. Oxycodone and naloxone can also be administered in "loose dose" regimens.

Linaclotide (Linzess) is a 14 -amino acid peptide that is an agonist of the luminal guanylate cyclase $\mathrm{C}$ receptors, which increases both intracellular and extracellular cyclic GMP. The increase in cyclic GMP activates the cystic fibrosis transmembrane conductance regulator, which results in increased secretions of luminal bicarbonate and chloride accelerating intestinal transit and causes laxation. Linaclotide is indicated for treatment in individuals with irritable bowel syndrome with constipation and chronic-idiopathic constipation in the US. Linaclotide is not yet FDA approved to treat $\mathrm{OIC}{ }^{40}$

\section{Clinical effectiveness of PAMORA treatment of OIC}

A systematic review and meta-analysis showed that certain PAMORAs were more effective than placebo in treating OIC with numbers-needed-to-treat of 3, 4, and 5 for methylnaltrexone, naloxone, and alvimopan, respectively. In this meta-analysis, the use of MOR antagonists was not associated with increased adverse events compared with placebo by individual drug. ${ }^{41}$ However, when all three MOR antagonists were pooled together and compared with placebo, there were significantly more adverse events in the antagonist group and a number-needed-to-harm of $14 .^{41}$

Agents that reduce OIC are considered to have at least the theoretical potential of reducing opioid analgesia. However, in PAMORA trials of clinical efficacy, analgesia disruption is not reported. In a randomized double-blind clinical study of alvimopan in noncancer OIC patients $(n=522)$, there was no evidence of opioid antagonism even at the higher doses in the study (study doses were $0.5 \mathrm{mg}$ alvimopan twice daily, $1 \mathrm{mg}$ once daily, and $1 \mathrm{mg}$ twice daily). ${ }^{42} \mathrm{In}$ an analysis of 
Table I Recent clinical studies on PAMORAs and the secretory drug lubiprostone with key findings

\begin{tabular}{llll}
\hline Study & Patients/doses & $\begin{array}{l}\text { Constipation-related } \\
\text { end points }\end{array}$ & Constipation-related results Of note \\
\hline
\end{tabular}

\section{Alvimopan}

Webster et al, ${ }^{42} 2008$

RCT DB PC

8 wks

Spierings et al, ${ }^{44} 2015$

PC DB studies

9 months

\section{Methylnaltrexone}

lyer et al, ${ }^{45} 201 \mathrm{l}$

RCT 4 wk

Michna et al, ${ }^{46} 201 \mathrm{I}$

RCT DB 4 wk

Nalamachu et al, ${ }^{47} 2015$ Responder analysis of two RCTs
522 patients with noncancer pain and opioid-induced bowel dysfunction were randomized to alvimopan $0.5 \mathrm{mg}$ BID,

I mg alvimopan QD, I mg alvimopan BID, or placebo

836 noncancer pain patients with OIC randomized to lubiprostone $24 \mu \mathrm{g}$ or placebo BID

439 noncancer chronic pain patients with $\mathrm{OIC}$ received lubiprostone $24 \mu \mathrm{g}$ BID

469 noncancer pain patients with OIC were randomized to $\mathrm{MN}$ once a day, every other day, or placebo

460 noncancer pain patients with OIC randomized to $M N$ $<12 \mathrm{mg}$ QD or every other day (alternating with placebo)

Two Phase III RCTs ( $n=288$ ) in post hoc analysis of responder population

Patients were treated with $0.15 \mathrm{mg} / \mathrm{kg}$ or $0.30 \mathrm{mg} / \mathrm{kg} \mathrm{MN}$ or placebo

Viscusi et al, ${ }^{48} 2016$ RCT + OLE

I 34 placebo-treated patients median $150 \mathrm{mg} / \mathrm{d}$ MEQ with
Weekly SBM over baseline symptoms

SBM over baseline symptoms

Rescue medication use, weekly SBM frequency symptoms

Constipation symptoms self-reported by patients based on questionnaire

Bowel movement count, time of bowel movement, straining, sense of complete evacuation, Bristol Stool Form Scales, QoL

RFBM within 4 hours of first dose $<3$ RFBM weekly taking $\geq 50 \mathrm{mg} / \mathrm{d}$ MEQ; randomized to $12 \mathrm{mg} / \mathrm{d}$ of $\mathrm{MN}$ or placebo for 4 wks (RCT) then OLE for 8 wks with MN 12 mg/d as needed

RFBM within 4 hours of dose; $\geq 3$ RFBM per week; an increase of at least one RFBM per week over baseline
Significantly more mean weekly SBMs over initial 3 wks of treatment with alvimopan $0.5 \mathrm{mg}$ BID, alvimopan I mg QD, and alvimopan I mg BID vs placebo along with symptomatic improvement

SBM frequency vs baseline was significantly higher at wk 8 $(P=0.005)$ and overall $(P=0.004)$ in lubiprostone vs placebo patients. Lubiprostone patients had improved symptoms and patients rated it more effective than placebo for II of the 12 wks $(P<0.05)$

Rescue medication use decreased from the first to ninth month (33.0\%-18.6\%) and mean weekly SBM increased significantly over baseline at all months $(P<0.00 \mathrm{I}$, range $4.9-5.3$ vs I.4 at baseline)

In the MN daily group, significant improvements occurred for rectal symptoms, stool symptoms, and global scores vs placebo. In the MN every other day group, significant improvements over placebo occurred in stool symptoms and global scores $34.2 \%$ of $M N$ patients had RFBM within 4 hours of first dose vs 9.9\% placebo group $(P<0.00 \mathrm{I})$. NNT $\sim 4$. MN patients had shorter time to first RFBM and greater increase in number of RFBMs per week $(P<0.00 I$ and $P<0.05$, respectively)

$>50 \%$ of $\mathrm{MN}$ patients (both doses) had a RFBM within 4 hours of dosing compared with $14.6 \%$ of placebo patients $(P<0.000 \mathrm{I})$
9.7\% (placebo) and 45.9\% (MN) patients experienced an RFBM within 4 hours of first dose during RCT. $70 \%$ of placebo patients who crossed over to $M N$ had $\geq 3$ RFBM a week and an increase of at least one RFBM over baseline
The best

benefit-to-risk profile occurred with alvimopan $0.5 \mathrm{mg}$ BID
Largest differences between $\mathrm{MN}$ and placebo occurred in patients taking doses of $0.30 \mathrm{mg} / \mathrm{kg}$ and who had a noncancer primary diagnosis (70.0\% vs $12.8 \%$, $\mathrm{P}<0.00 \mathrm{I}$ )

Results in the OLE were durable $>8$ wks 
Table I (Continued)

\begin{tabular}{lll}
\hline Study & Patients/doses & $\begin{array}{l}\text { Constipation-related Constipation-related results } \\
\text { end points }\end{array}$ \\
\hline
\end{tabular}

\section{Naloxegol}

Chey et al,' 2014

Two identical Phase III

RCT DB studies

I2 wk ITT

Tack et al, ${ }^{49} 2015$

Pooled data from two

DB RCTs 12 wk

\section{Oxycodone/naloxone}

Blagden et al,,$^{50} 2014$

Pooled analysis from

extensions of two

Phase III trials

Koopmans et al, ${ }^{51} 2014$

Pooled analysis from

RCTs

Lowenstein et al, ${ }^{52}$

2009

RCT DB DD

PG MC study

4 wk

Meissner et al, ${ }^{53} 2009$

RCT DB

4 wk study then 2 wks

oxycodone only

Poelaert et al, ${ }^{54} 2015$

$\mathrm{NI} O b \mid 2 \mathrm{wk}$

Sanders et al, ${ }^{55} 2015$

R DB

Ascending dose

$6 \mathrm{wk}$
Outpatients with noncancer pain and OIC ( $n=4,652$ and 5,700 )

Once daily dose of $12.5 \mathrm{mg}$ or $25 \mathrm{mg}$ naloxegol or placebo

720 noncancer pain patients with laxative-refractory OIC randomized to be treated daily with $25 \mathrm{mg}$ naloxegol, $12.5 \mathrm{mg}$ naloxegol, or placebo

Pooled data from 474 patients with moderate to severe chronic pain taking OXN PR or OXY PR

(Pooled data from 75) LROIC patients treated with OXN PR (20-120 mg/d) for 4 wks or 12 wks

265 OIC patients with moderate to severe chronic noncancer pain taking 60-80 mg/d OXN PR or OXY PR

202 chronic pain patients ( $97.5 \%$ with noncancer pain) on stable oral oxycodone therapy (40-80 $\mathrm{mg} / \mathrm{d}$ ) randomized to receive $10 \mathrm{mg} / \mathrm{d}, 20 \mathrm{mg} / \mathrm{d}$, or $40 \mathrm{mg} / \mathrm{d}$ naloxone or placebo (loose dose combination therapy)

68 LROIC with severe chronic Laxative use, QoL pain ( $91 \%$ noncancer pain) treated for 90 days with OXN PR or OXY PR (median dose $20 \mathrm{mg} / \mathrm{d}$ )

40 noncancer pain patients with $\mathrm{OIC}$ randomized into four groups in ascending dose design $(2.5 \mathrm{mg}, 5 \mathrm{mg}, 10 \mathrm{mg}$, and $20 \mathrm{mg}$ sustained-release naloxone) vs placebo given once a day for 3 wks then BID for 4-6 wks $\geq 3$ SBM per week and increase of $\geq 1$ SBM for weeks $\geq 9$ of the 12 wk study and for $\geq 3$ wks of the last 4 wks

Time to first postdose laxation, SBMs, OIC symptoms

Analgesia and bowel function using BPI and $\mathrm{BFI}$, respectively; laxative use

Analgesia and bowel function using BPI and $\mathrm{BFI}$, respectively; laxative use

$\mathrm{BFI}$ and laxative use

$\mathrm{BFI}$

SBM change over baseline
The naloxegol $25 \mathrm{mg}$ group was significantly more likely than placebo to meet end points (in one of the studies $44.4 \%$ vs $29.4 \%, P=0.001$ ). Pain scores and daily opioid doses were similar among groups. AEs were highest in the $25 \mathrm{mg}$ naloxegol group

Response rates highest in $25 \mathrm{mg}$ naloxegol patients $(P<0.00 \mathrm{I})$ and $12.5 \mathrm{mg}(P=0.005)$ vs placebo. Median times to first postdose SBM were 7.6 hours, 19.2 hours, and 4I.I hours for naloxegol $25 \mathrm{mg}$, $12.5 \mathrm{mg}$, and placebo, respectively

At start of extension, mean BFI scores were 44.3 for OXY PR and 29.8 for OXN PR groups; I wk later scores were similar (26.5 and 27.5, respectively) with durable results Significant improvements in bowel function with OXN PR (BFI score reduction 2I.2). Number of patients with normal BFI score increased from $9.5 \%$ at baseline to $43.1 \%$ at day 15 of OXN PR OXN PR had significantly better BFI scores at 4 wks $(P<0.000 \mathrm{I})$ vs OXY PR patients. OXN PR patients had a median of 3.0 CSBM per wk at 4 wks compared with OXY PR patients at I.0. OXN PR patients took less laxative Naloxone $20 \mathrm{mg}$ and $40 \mathrm{mg}$ significantly improved bowel function through end of maintenance phase vs placebo $(P<0.05)$

OXN PR patients used significantly less laxatives $(P<0.00 I)$ and had significantly improved QoL scores vs OXY PR patients

Significant SBM improvements occurred at doses of $5 \mathrm{mg}, 10 \mathrm{mg}$, and $20 \mathrm{mg}$ sustained-release naloxone with mean changes in SBM over baseline ranging from $2.21 \mathrm{mg}$, $2.37 \mathrm{mg}, 4.1 \mathrm{l} \mathrm{mg}$, and $5.19 \mathrm{mg}$ for $2.5 \mathrm{mg}, 5 \mathrm{mg}, 10 \mathrm{mg}$, and $20 \mathrm{mg}$, respectively, vs I.38 for placebo
The time to first postdose SBM was significantly shorter with either dose of naloxegol than placebo (in study 4) or with $25 \mathrm{mg}$ only compared with placebo (study 5), $\mathrm{P}<0.0$ I both studies

$<10 \%$ of patients took laxatives regularly

During study, $36 \%$ of patients stopped using laxatives $(P<0.00 \mathrm{I})$

Analgesic efficacy was not diminished by naloxone. The study recommended a 2 : I dose ratio of oxycodone to naloxone

Response rate to OXN PR was $95 \%$

The highest incidence of TEAE occurred in the placebo group 
Table I (Continued)

\begin{tabular}{|c|c|c|c|c|}
\hline Study & Patients/doses & $\begin{array}{l}\text { Constipation-related } \\
\text { end points }\end{array}$ & Constipation-related results & Of note \\
\hline $\begin{array}{l}\text { Simpson et al, }{ }^{56} 2008 \\
\text { R DB MC trial } \\
\text { I } 2 \text { wk }\end{array}$ & $\begin{array}{l}322 \text { noncancer pain } \\
\text { patients taking } 20-50 \mathrm{mg} / \mathrm{d} \\
\text { oxycodone randomized to } \\
\text { oral oxycodone PR or oral } \\
\text { oxycodone/naloxone PR }\end{array}$ & $\mathrm{BFI}$ & $\begin{array}{l}\text { Oxycodone/naloxone significantly } \\
\text { improved BFI scores after } 4 \text { wks }\end{array}$ & $\begin{array}{l}\text { Analgesic efficacy was } \\
\text { similar in both groups }\end{array}$ \\
\hline $\begin{array}{l}\text { Ueberall and Mueller- } \\
\text { Schwefe, },^{57} 2015 \\
\text { R OL study with } \\
\text { blinded end points } \\
12 \text { wk }\end{array}$ & $\begin{array}{l}453 \text { patients with low back } \\
\text { pain randomized to } \mathrm{OXN} \text {, } \\
\text { OXY, or morphine }\end{array}$ & $\begin{array}{l}\text { Patients without an AE- } \\
\text { related discontinuation } \\
\text { with a combined } \\
\text { end point of } \geq 50 \% \\
\text { improvement in pain } \\
\text { intensity, disability, } \\
\text { and QoL and a } \leq 50 \% \\
\text { worsening of bowel } \\
\text { function }\end{array}$ & $\begin{array}{l}22.2 \% \text { of } O X N \text { vs } 9.3 \% \text { of } O X Y \\
\text { and } 6.3 \% \text { of morphine patients } \\
\text { met the end point with significant } \\
\text { differences between } O X N \text { and } \\
\text { OXY }(P<0.00 I) \text { and } O X N \text { and } \\
\text { morphine }(P<0.00 \mathrm{I}) \text { but no } \\
\text { significant difference between } \\
\text { OXY and morphine. TEAEs } \\
\text { occurred in } 45 \text { OXN, } 69 \text { OXY, } \\
\text { and } 75 \text { morphine patients and } \\
\text { overall were } 5 \mathrm{I} \% \mathrm{Gl} \text { in nature }\end{array}$ & \\
\hline
\end{tabular}

Note: Studies are presented and grouped by agent and then in alphabetical order by first author.

Abbreviations: AE, adverse event(s); BFI, Bowel Function Index; BID, twice daily; BPI, brief pain inventory; CSBM, complete spontaneous bowel movement; DB, double-blind; $\mathrm{DD}$, double-dummy; ITT, intention-to-treat; LROIC, laxative-refractory OIC patients; MC, multicenter; MEQ, morphine equivalent; MN, methylnaltrexone; NI, noninterventional; NNT, number needed to treat; Ob, observational; OIC, opioid-induced constipation; OL, open-label; OLE, open-label extension; OXN, oxycodone/naloxone fixeddose combination product; OXN PR, oxycodone/naloxone fixed-dose combination product in prolonged-release formulation; OXY, oxycodone; PC, placebo-controlled; PG, parallel group; PR, prolonged release; QD, once daily; QoL, quality of life; R, randomized; RCT, randomized controlled trial; RFBM, rescue-free bowel movement, defined as a bowel movement not occurring within 24 hours of rescue laxative use; SBM, spontaneous bowel movement; TEAE, treatment-emergent adverse event(s); wk, week.

Phase III studies of subcutaneous methylnaltrexone for use in OIC patients with chronic noncancer pain, methylnaltrexone did not adversely affect central opioid analgesia. ${ }^{58}$ Methylnaltrexone is characterized by "responders," who report drug efficacy in at least two of the first four doses and who derive particular benefit from this subcutaneous agent. ${ }^{46}$ In a post hoc analysis of a randomized clinical trial of subcutaneous methylnaltrexone for OIC, $\sim 42 \%$ of patients could be categorized as responders. Oxycodone/naloxone used for chronic noncancer pain can improve patients' quality of life, minimize the symptoms of constipation, and does not reduce central analgesic efficacy. ${ }^{55,59,60} \mathrm{Naloxegol}$ has been identified as an effective agent in reducing OIC without compromising central pain relief. ${ }^{34}$ Thus, PAMORAs appear to be able to reduce OIC without compromising analgesic efficacy of the opioids. ${ }^{61}$ Numerous clinical studies have evaluated the efficacy of these agents in treating OIC vs placebo (Table 1).

\section{Clinical safety of secretory drug lubiprostone in the treatment of OIC}

Lubiprostone is indicated for treatment of OIC and chronic constipation and may be used in the outpatient setting. In a placebo-controlled double-blind study of 439 noncancer pain patients with OIC, lubiprostone patients received $24 \mu \mathrm{g}$ lubiprostone twice daily for up to 9 months. ${ }^{44}$ Overall, $24.6 \%$ of patients reported some treatment-emergent adverse event(s), of which the most common were nausea $(5.0 \%)$, diarrhea (4.6\%), headache (1.6\%), and vomiting (1.4\%). No treatment-emergent serious adverse events were observed. ${ }^{44}$ In randomized, double-blind, placebo-controlled studies at 79 US and Canadian centers, 836 OIC patients were randomized to placebo or $24 \mu \mathrm{g}$ lubiprostone twice a day for 12 weeks. ${ }^{43}$ No serious treatment-related adverse events occurred and the most commonly reported adverse events were nausea (16.8\% vs $5.8 \%$ for lubiprostone vs placebo, respectively), diarrhea ( $9.6 \%$ vs $2.9 \%)$, and abdominal distention (8.2\% vs $2.4 \%){ }^{43}$

Overall, the most common side effects associated with lubiprostone are mild to moderate nausea and diarrhea. ${ }^{61}$

\section{Clinical safety of PAMORA treatment of OIC}

Opioids are associated with well-documented side effects, but the adverse events associated with PAMORAs have been less well studied.

\begin{abstract}
Alvimopan
Alvimopan is indicated for short-term use only in hospitalized patients and is packaged with a black-box warning for the potential risk of myocardial infarction associated with long-term use. ${ }^{62}$ In a study of alvimopan in noncancer OIC patients $(n=522)$, the most frequently reported adverse events were abdominal pain, nausea, and diarrhea; adverse events occurred more often in higher-dosage than in lower-dosage
\end{abstract}


groups (study doses were alvimopan $0.5 \mathrm{mg}$ twice daily, $1 \mathrm{mg}$ once daily, and $1 \mathrm{mg}$ twice daily). ${ }^{42}$

\section{Methylnaltrexone}

Methylnaltrexone is administered by subcutaneous injection. In a clinical trial of methylnaltrexone ( $\mathrm{n}=134$ OIC patients), adverse events were reported by $32.8 \%$ of placebo patients in the 4-week randomized clinical trial phase of the study compared with $43.3 \%$ of patients in the 8 -week open-label extension phase when prior placebo patients could take methylnaltrexone as needed. ${ }^{48}$ The most frequently reported adverse events were abdominal pain, nausea, and urinary tract infections. Serious adverse events were reported in $<1 \%$ of patients during the RCT and in $3.0 \%$ of patients during the open-label extension phase, but none were considered to be related to the study drug.

In a post hoc analysis of responders from two Phase II placebo-controlled randomized trials of methylnaltrexone for 288 OIC patients, the most frequently reported adverse events (pooling results for $0.15 \mathrm{mg} / \mathrm{kg}$ and $0.30 \mathrm{mg} / \mathrm{kg}$ subcutaneous dosing) were abdominal pain $(27.9 \%$ vs $9.8 \%$ placebo), flatulence $(13.3 \%$ vs $5.7 \%)$, and nausea $(10.9 \%$ vs $4.9 \%) .{ }^{47}$

\section{Naloxegol}

Naloxegol is the first oral PAMORA approved in the US, making it particularly convenient for chronic pain outpatients. In a 52-week open-label randomized, parallel-group Phase III study, patients taking from 30 to 1,000 morphine equivalents daily for noncancer pain who developed OIC were randomized to receive daily $25 \mathrm{mg}$ naloxegol or usual care (investigator's choice of laxative). ${ }^{63}$ The safety set $(n=804)$ of OIC patients experienced adverse events at a rate of $81.8 \%$ (naloxegol) and $72.2 \%$ (usual care). Those treatment-emergent adverse events that occurred more frequently with naloxegol than with usual care were abdominal pain $(17.8 \%$ vs $3.3 \%)$, diarrhea (12.9\% vs $5.9 \%)$, nausea (9.4\% vs $4.1 \%)$, headache ( $9.0 \%$ vs $4.8 \%)$, flatulence $(17.8 \%$ vs $3.3 \%)$, and upper abdominal pain (5.1\% vs $1.1 \%){ }^{63}$

In a dose-escalation study, 207 OIC patients on stable opioid regimens ranging from 30 to 1,000 morphine equivalents per day (for at least 2 weeks) were randomized to receive $5 \mathrm{mg}, 25 \mathrm{mg}$, or $50 \mathrm{mg}$ daily of naloxegol after a 1 -week run-in period with placebo. ${ }^{64}$ Naloxegol was well tolerated across all doses with the most common adverse events being abdominal pain, diarrhea, and nausea. At doses of $\leq 25 \mathrm{mg} / \mathrm{d}$, the majority of adverse events were mild and transient; adverse events increased in frequency and severity at $50 \mathrm{mg} / \mathrm{d}$ naloxegol. ${ }^{64}$
In a pooled analysis from two randomized double-blind clinical trials of daily naloxegol $25 \mathrm{mg}$ and $12.5 \mathrm{mg}$ vs placebo $(n=720)$, there was a higher rate of overall adverse events in the naloxegol $25 \mathrm{mg}$ group (63.1\%) compared with the $12.5 \%$ group (50.6\%) and placebo (50.0\%). ${ }^{49}$ The rate of serious adverse events was similar across all three groups.

\section{Oxycodone/naloxone combination}

Oxycodone can be combined with naloxone in the form of two oral agents prescribed as separate single-entity agents (so-called "loose dosing") or in oral fixed-dose combination products. Such combination drugs may not be available in all geographies. In a noninterventional observational study of 68 patients with severe pain (91\% noncancer) and laxativerefractory $\mathrm{OIC}$, oxycodone/naloxone significantly reduced the use of laxatives and significantly improved quality of life compared with patients taking oxycodone alone. ${ }^{54}$ In this study, $2.9 \%$ of patients $(n=2)$ reported adverse events, none of which were serious.

In a pooled analysis of data from two randomized clinical trials ( $\mathrm{n}=75$ patients), adverse events were reported in approximately one-third of patients $(27.5 \%$ in one study, $40.0 \%$ in the other). ${ }^{51}$ The most frequently reported adverse events were nausea (9.3\%), constipation (9.3\%), and vomiting $(8.0 \%)$. Serious adverse events were more frequently reported in patients with cancer pain than noncancer pain.

Pooled data from the 52-week extension phases of two randomized clinical trials of prolonged-release oxycodone/naloxone found that $78.1 \%$ of all patients reported at least one adverse event, $36.7 \%$ of which were musculoskeletal in nature and deemed to be associated with the patients' underlying conditions rather than the study drug. ${ }^{50}$ Treatment-related adverse events occurred in $46.0 \%$, with the most common broad categories of side effects such as GI (20.3\%), general disorders such as fatigue (9.5\%), and nervous system disorders (8.6\%). Serious adverse events deemed related to the study drug occurred in 20 patients $(4.2 \%)$.

In a randomized clinical trial $(n=265)$ comparing prolonged-release formulations of oxycodone/naloxone with oxycodone alone, slightly more adverse events occurred in the oxycodone/naloxone group than in the oxycodone group. ${ }^{52}$ Investigators suggested that this can be attributed to a spike in abdominal pain in the oxycodone/naloxone group during the first week after randomization, which might be associated with an increase in gut motility. The number of treatment-related adverse events was $37.7 \%$ for oxycodone/ naloxone patients compared with $29.6 \%$ of oxycodone 
patients. The most frequently reported adverse events were similar in both groups: nausea, pain, and headache.

In a double-blind randomized clinical trial of oral oxycodone (40-80 mg/d) combined with oral naloxone $(10 \mathrm{mg} / \mathrm{d}$, $20 \mathrm{mg} / \mathrm{d}$, or $40 \mathrm{mg} / \mathrm{d})$ or placebo $(\mathrm{n}=202)$, adverse events were comparable across all treatment groups (range 62.7\%-70.0\%). ${ }^{53}$ In this study, the oxycodone and naloxone combination was administered as two separate products ("loose dose"). No relationship between dose and adverse events could be found and most adverse events were mild to moderate; no deaths occurred. In the dosing group that received medication in the ratio of 1.5:1 of oxycodone to naloxone, diarrhea occurred in $50 \%$ of patients compared with $29.4 \%$ in the $2: 1$ oxycodone/ naloxone group. Diarrhea was transient, but it was the main reason that patients discontinued naloxone.

In a randomized trial comparing oxycodone and oxycodone/naloxone in chronic noncancer pain patients $(n=322)$, most adverse events in both groups could be classified as GI in nature, but GI adverse events were fewer in the oxycodone/naloxone than the oxycodone only group. ${ }^{56}$ In this study, $6.8 \%$ of oxycodone only patients and $5.6 \%$ of oxycodone/naloxone patients experienced diarrhea.

A Phase II, placebo-controlled study of sustained-release naloxone administered to 40 noncancer pain patients with OIC found no serious adverse events in any group and the highest incidence of treatment-emergent adverse events in the placebo group. ${ }^{55}$ The study evaluated sustained-release naloxone doses of $2.5 \mathrm{mg}, 5 \mathrm{mg}, 10 \mathrm{mg}$, and $20 \mathrm{mg}$ with drugs given once daily for 3 weeks and then twice daily for the subsequent 3 weeks (6-week study). Adverse effects were similar in all active treatment groups at all doses.

\section{Future directions in OIC treatments}

The burgeoning chronic noncancer pain population, the "graying" of America, and increased recognition of the utility of opioids for pain control imply that OIC will be a persistent and burgeoning clinical problem. Novel drug targets and agents are being actively studied. A naltrexamine derivative, 17-cyclopropylmethyl-3,14 $\beta$-dihydroxy-4,5 $\alpha$-epoxy- $6 \beta$ ( $4^{\prime}$-pyridylcarboxamido)morphinan, acts selectively on the MOR and may be useful for future product development for OIC. ${ }^{65}$

\section{Clinical considerations}

The treatments for OIC utilize different mechanisms of action and in some cases, it may be appropriate to combine different OIC treatments with different mechanisms of action in order to improve outcomes, although this approach has not yet been rigorously studied. ${ }^{4}$ OIC therapy with multiple agents with complementary mechanisms of action may be particularly useful in patients with OIC and warrants further investigation. For any number of reasons, prescribers may be reticent to recommend OIC therapy with multiple agents. In a study of prescribing practices for all forms of constipation, including but not limited to $\mathrm{OIC}$, the prescribing of multiple agents is declining $(17 \%$ vs $11 \%, P<0.05)$, while monotherapy (prescribing a single agent) is increasing $(21 \%$ vs $29 \%, P<0.05) .{ }^{66}$ In this particular study (89.6 million office visits for constipation), elderly patients were less likely than other patients to be prescribed therapy using more than one agent. Further study is needed on the use of multiple agents for treating OIC.

While opioids can be cost-effective analgesic agents, the cost-effectiveness of OIC therapy must also be considered in today's cost-conscious health care environment. Prescribing a PAMORA to treat OIC adds to drug costs, but these costs may offset against the costs of treating OIC. To quantify costs associated with OIC, a retrospective study of adult data from 2007 to 2011 using Truven Health MarketScan Commercial and Medicare databases ( $\mathrm{n}=13,808$ "nonelderly" and 2,958 elderly patients) was conducted. ${ }^{67}$ Overall, OIC patients had significantly more hospital admissions than patients without OIC ( $33 \%$ vs $22 \%$, nonelderly $P<0.001$; and $51 \%$ vs $31 \%$, elderly, $P<0.001$ ), longer hospital length-of-stay (3.0 \pm 8.4 days vs $1.0 \pm 3.0$ days nonelderly and $5.2 \pm 12.2$ days vs $2.1 \pm 4.0$ days, elderly; $P<0.001$ for both) and higher health care costs $(\$ 23,631 \pm \$ 67,209$ vs $\$ 12,652 \pm \$ 19,717$ for nonelderly and $\$ 16,923 \pm \$ 38,191$ vs $\$ 11,117 \pm \$ 19,525$ for elderly; $P<0.05$ for both).

In a study from the UK, the incremental cost of oxycodone/naloxone was found to be $£ 159.68$ for the average course of treatment (301 days) compared with oxycodone as a single-entity product. ${ }^{68}$ Oxycodone/naloxone offered an incremental gain in quality-adjusted life-years (QALY) of 0.027 , establishing an incremental cost-effectiveness ratio of $£ 5,841.56$ per QALY. The typical threshold used for incremental cost-effectiveness ratio is $£ 20,000$ such that oxycodone/naloxone was a cost-effective treatment. In fact, probabilistic sensitivity analysis showed that oxycodone/ naloxone had a $96.6 \%$ probability of being cost-effective at the $£ 20,000$ threshold. The investigators concluded that oxycodone/naloxone was a cost-effective treatment option for chronic pain patients suffering from OIC.

This demonstrates that the incremental expenses of OIC can be substantial. In a study of patients treated with 
oxycodone/naloxone, the incremental costs for oxycodone/ naloxone over oxycodone were offset with higher QALY for patients and reduced consumption of laxatives or other resources necessary to manage OIC. ${ }^{69}$ Cost-effectiveness studies can provide important data, but in the real-world clinical setting, multiple prescribers, health care organizations, and payers complicate the picture.

\section{Discussion}

Laxative-refractory OIC can be a persistent and distressing side effect of chronic opioid therapy, which may be treatment limiting. At the onset of opioid therapy, patients should be educated about OIC and encouraged to report their symptoms. Since constipation and bowel habits can be embarrassing subjects for some patients, clinicians may have to prompt patients to discuss this important topic frankly.

At the outset of opioid therapy, it is prudent to initiate a bowel regimen for the patient with the understanding that OIC may not respond in the long term (or at all) to this type of approach. Bowel regimens are conservative therapy and there will be a subset of patients who will respond to this approach. Using two or more laxatives with different mechanisms of action may be helpful. Patients should be counseled not to abandon hope if the bowel regimen and conventional laxative(s) fail to offer desired results. For such patients, PAMORAs can be very helpful and may improve quality of life and function.

The advent of PAMORAs has the potential to allow for long-term safe use of opioid therapy in noncancer patients with moderate to severe or very severe pain. Studies demonstrate that PAMORAs reduce GI symptoms and do not adversely impact analgesic benefit of the opioid therapy. The incidence of side effects must be taken into account as these agents may be associated with potentially treatment-limiting adverse events, such as abdominal pain. Oxycodone and naloxone likewise reduce GI symptoms with no compromise in analgesic efficacy. Future developments may bring more promising agents to market to better treat OIC.

\section{Conclusion}

OIC is a frequent and distressing side effect of opioid therapy that can cause patients to discontinue analgesic therapy. Conventional laxatives and conservative bowel regimens of lifestyle changes are often not effective to combat OIC, which occurs because of the effect of the opioid on the MOR of the GI tract. Novel products such as PAMORAs have been shown to be safe and effective in treating laxative-resistant OIC, although there are associated side effects, notably abdominal pain and discomfort. Further research is ongoing, which may result in more agents in this category in the future. PAMORAs may allow patient relief from OIC, improve quality of life, and permit adequate analgesia even in the face of moderate to severe chronic noncancer pain.

\section{Disclosure}

JVP is a speaker, researcher, and/or consultant for Astra Zeneca, Daiichi Sankyo, ENDO, Collegium, Grunenthal, Purdue Pharma, Mundipharma and Shionogi. He has received no funding in relationship to this project/manuscript. RBR is a speaker, consultant, and/or basic science investigator for several pharmaceutical companies but receives no royalty (cash or otherwise) from the sale of any product. CF, GPZ, and JPIII are research fellows and JL is director of scientific communications for NEMA Research, Inc., a clinical research organization which is provides product development services to a number of pharmaceutical companies. The other authors have nothing to disclose.

\section{References}

1. Chey WD, Webster L, Sostek M, Lappalainen J, Barker PN, Tack J. Naloxegol for opioid-induced constipation in patients with noncancer pain. N Engl J Med. 2014;370(25):2387-2396.

2. Nilsson M, Poulsen JL, Brock C, et al. Opioid-induced bowel dysfunction in healthy volunteers assessed with questionnaires and MRI Eur J Gastroenterol Hepatol. 2016;28(5):514-524.

3. Poulsen JL, Nilsson M, Brock C, Sandberg TH, Krogh K, Drewes AM. The impact of opioid treatment on regional gastrointestinal transit. J Neurogastroenterol Motil. 2016;22(2):282-291.

4. Wald A. Constipation: advances in diagnosis and treatment. JAMA 2016;315(2):185-191.

5. McCaffery M, Pasero CL. Pain ratings: the fifth vital sign. Am JNurs. 1997 97(2):15-16

6. International Pain Summit Of The International Association For The Study Of Pain. Declaration of Montreal: declaration that access to pain management is a fundamental human right. J Pain Palliat Care Pharmacother. 2011;25(1):29-31.

7. Nelson AD, Camilleri M. Chronic opioid induced constipation in patients with nonmalignant pain: challenges and opportunities. Ther $\mathrm{Adv}$ Gastroenterol. 2015;8(4):206-220.

8. Bell T, Annunziata K, Leslie JB. Opioid-induced constipation negatively impacts pain management, productivity, and health-related quality of life: findings from the national health and wellness survey. $J$ Opioid Manag. 2009;5(3):137-144.

9. Akbarali HI, Inkisar A, Dewey WL. Site and mechanism of morphine tolerance in the gastrointestinal tract. Neurogastroenterol Motil. 2014 26(10): 1361-1367.

10. Wald A. Constipation: pathophysiology and management. Curr Opin Gastroenterol. 2015;31(1):45-49.

11. Bagnol D, Mansour A, Akil H, Watson SJ. Cellular localization and distribution of the cloned mu and kappa opioid receptors in rat gastrointestinal tract. Neuroscience. 1997;81(2):579-591.

12. McKay J, Linaker B, Turnberg L. Influence of opiates on ion transport across rabbit ileal mucosa. Gastroenterology. 1981;80: 279-284.

13. Fickel J, Bagnol D, Watson SJ, Akil H. Opioid receptor expression in the rat gastrointestinal tract: a quantitative study with comparison to the brain. Brain Res Mol Brain Res. 1997;46(1-2):1-8. 
14. Smith H, McCleane G, Thompson G. Optimizing Pharmacologic Outcomes: Assessing and Managing Opioid Side Effects. New York, NY: Oxford University Press; 2013.

15. Gupta A. Improving the recognition and diagnosis of opioid-induced constipation in clinical practice. J Fam Pract. 2015;64(10 suppl 1):pii: jfp_64101.

16. [No authors listed] Naloxegol for opioid-induced constipation. Drug Ther Bull. 2015;53(12):138-140.

17. Gaertner J, Siemens W, Camilleri M, et al. Definitions and outcome measures of clinical trials regarding opioid-induced constipation: a systematic review. J Clin Gastroenterol. 2015;49(1):9-16.

18. Arce D, Ermocilla C, Costa H. Evaluation of constipation. Am Fam Physician. 2002;11:2283-2290.

19. Drossman DA. Functional gastrointestinal disorders: history, pathophysiology, clinical features and Rome IV. Gastroenterology. 2016;pii: S0016-5085(16)00223-7.

20. Szigethy E, Schwartz M, Drossman D. Narcotic bowel syndrome and opioid-induced constipation. Curr Gastroenterol Rep. 2014; 16(10):410.

21. Longstreth GF, Thompson WG, Chey WD, Houghton LA, Mearin F, Spiller RC. Functional bowel disorders. Gastroenterology. 2006;130(5):1480-1491.

22. Anantharamu T, Sharma S, Gupta AK, Dahiya N, Singh Brashier DB, Sharma AK. Naloxegol: first oral peripherally acting mu opioid receptor antagonists for opioid-induced constipation. J Pharmacol Pharmacother. 2015;6(3):188-192.

23. Argoff CE, Brennan MJ, Camilleri M, et al. Consensus recommendations on initiating prescription therapies for opioid-induced constipation. Pain Med. 2015;16(12):2324-2337.

24. Hunold KM, Smith SA, Platts-Mills TF. Constipation prophylaxis is rare for adults prescribed outpatient opioid therapy from U.S. Emergency Departments. Acad Emerg Med. 2015;22(9):1118-1121.

25. Siemens W, Gaertner J, Becker G. Advances in pharmacotherapy for opioid-induced constipation - a systematic review. Expert Opin Pharmacother. 2015;16(4):515-532.

26. Badke A, Rosielle DA. Opioid induced constipation part I: established management strategies \#294. J Palliat Med. 2015;18(9): 799-800.

27. Pappagallo M. Incidence, prevalence, and management of opioid bowel dysfunction. Am J Surg. 2001;182(5A suppl):11S-18S.

28. Koopmans-Klein G, Wagemans MF, Wartenberg HC, Van Megen YJ, Huygen FJ. The efficacy of standard laxative use for the prevention and treatment of opioid induced constipation during oxycodone use: a small Dutch observational pilot study. Expert Rev Gastroenterol Hepatol. 2015;26:1-7.

29. Thomas J. Opioid-induced bowel dysfunction. J Pain Symptom Manage. 2008;35(1):103-113.

30. LoCasale RJ, Datto CJ, Margolis MK, Tack J, Coyne KS. The impact of opioid-induced constipation among chronic pain patients with sufficient laxative use. Int J Clin Pract. 2015;69(12):1448-1456.

31. Weber HC. Opioid-induced constipation in chronic noncancer pain. Curr Opin Endocrinol Diabetes Obes. 2016;23(1):11-17.

32. Alvimopan (Entereg) for postoperative ileus. Med Lett Drugs Ther. 2008; 50(1300):93-94.

33. Naloxegol (Movantik) for opioid-induced constipation. JAMA. 2016; 315(2):194-195.

34. Bruner H, Atayee R, Endmonds K, Buckholz G. Clinical utility of naloxogel in the treatment of opioid-induced constipation. J Pain Res. 2015; 8:289-294.

35. Garnock-Jones KP. Naloxegol: a review of its use in patients with opioid-induced constipation. Drugs. 2015;75(4):419-425.

36. Camilleri M, Bharucha AE, Ueno R, et al. Effect of a selective chloride channel activator, lubiprostone, on gastrointestinal transit, gastric sensory, and motor functions in healthy volunteers. Am J Physiol Gastrointest Liver Physiol. 2006;290(5):G942-G947.
37. Rao S, Weber HC. New treatment targets for the management of irritable bowel syndrome. Curr Opin Endocrinol Diabetes Obes. 2014; 21(1):9-14.

38. Johanson JF, Ueno R. Lubiprostone, a locally acting chloride channel activator, in adult patients with chronic constipation: a double-blind, placebo-controlled, dose-ranging study to evaluate efficacy and safety. Aliment Pharmacol Ther. 2007;25(11):1351-1361.

39. [No authors listed] Targinact - opioid pain relief without constipation? Drug Ther Bull. 2010;48(12):138-141.

40. Rao SS, Rattanakovit K, Patcharatrakul T. Diagnosis and management of chronic constipation in adults. Nat Rev Gastroenterol Hepatol. 2016; 13(5):295-305.

41. Ford AC, Brenner DM, Schoenfeld PS. Efficacy of pharmacological therapies for the treatment of opioid-induced constipation: systematic review and meta-analysis. Am J Gastroenterol. 2013;108(10): 1566-1574; quiz 1575.

42. Webster L, Jansen JP, Peppin J, et al. Alvimopan, a peripherally acting mu-opioid receptor (PAM-OR) antagonist for the treatment of opioidinduced bowel dysfunction: results from a randomized, double-blind, placebo-controlled, dose-finding study in subjects taking opioids for chronic non-cancer pain. Pain. 2008;137(2):428-440.

43. Cryer B, Katz S, Vallejo R, Popescu A, Ueno R. A randomized study of lubiprostone for opioid-induced constipation in patients with chronic noncancer pain. Pain Med. 2014;15(11):1825-1834.

44. Spierings EL, Rauck R, Brewer R, Marcuard S, Vallejo R. Long-term safety and efficacy of lubiprostone in opioid-induced constipation in patients with chronic noncancer pain. Pain Pract. Epub 2015 Aug 29.

45. Iyer SS, Randazzo BP, Tzanis EL, et al. Effect of subcutaneous methylnaltrexone on patient-reported constipation symptoms. Value Health. 2011;14(1):177-183.

46. Michna E, Blonsky ER, Schulman S, et al. Subcutaneous methylnaltrexone for treatment of opioid-induced constipation in patients with chronic, nonmalignant pain: a randomized controlled study. J Pain. 2011; 12(5):554-562.

47. Nalamachu SR, Pergolizzi J, Taylor R Jr, et al. Efficacy and tolerability of subcutaneous methylnaltrexone in patients with advanced illness and opioid-induced constipation: a responder analysis of 2 randomized, placebo-controlled trials. Pain Pract. 2015;15(6):564-571.

48. Viscusi ER, Barrett AC, Paterson C, Forbes WP. Efficacy and safety of methylnaltrexone for opioid-induced constipation in patients with chronic noncancer pain: a placebo crossover analysis. Reg Anesth Pain Med. 2016;41(1):93-98.

49. Tack J, Lappalainen J, Diva U, Tummala R, Sostek M. Efficacy and safety of naloxegol in patients with opioid-induced constipation and laxative-inadequate response. United European Gastroenterol J. 2015; 3(5):471-480.

50. Blagden M, Hafer J, Duerr H, Hopp M, Bosse B. Long-term evaluation of combined prolonged-release oxycodone and naloxone in patients with moderate-to-severe chronic pain: pooled analysis of extension phases of two phase III trials. Neurogastroenterol Motil. 2014;26(12): 1792-1801.

51. Koopmans G, Simpson K, De Andres J, Lux EA, Wagemans M, Van Megen Y. Fixed ratio (2:1) prolonged-release oxycodone/naloxone combination improves bowel function in patients with moderate-tosevere pain and opioid-induced constipation refractory to at least two classes of laxatives. Curr Med Res Opin. 2014;30(11):2389-2396.

52. Lowenstein O, Leyendecker P, Hopp M, et al. Combined prolongedrelease oxycodone and naloxone improves bowel function in patients receiving opioids for moderate-to-severe non-malignant chronic pain: a randomised controlled trial. Expert Opin Pharmacother. 2009;10(4): 531-543.

53. Meissner W, Leyendecker P, Mueller-Lissner S, et al. A randomised controlled trial with prolonged-release oral oxycodone and naloxone to prevent and reverse opioid-induced constipation. Eur J Pain. 2009; 13(1):56-64. 
54. Poelaert J, Koopmans-Klein G, Dioh A, et al. Treatment with prolongedrelease oxycodone/naloxone improves pain relief and opioid-induced constipation compared with prolonged-release oxycodone in patients with chronic severe pain and laxative-refractory constipation. Clin Ther. 2015;37(4):784-792.

55. Sanders M, Jones S, Lowenstein O, Jansen JP, Miles H, Simpson K. New formulation of sustained release naloxone can reverse opioid induced constipation without compromising the desired opioid effects. Pain Med. 2015;16(8):1540-1550.

56. Simpson K, Leyendecker P, Hopp M, et al. Fixed-ratio combination oxycodone/naloxone compared with oxycodone alone for the relief of opioid-induced constipation in moderate-to-severe noncancer pain. Curr Med Res Opin. 2008;24(12):3503-3512.

57. Ueberall MA, Mueller-Schwefe GH. Safety and efficacy of oxycodone/ naloxone vs. oxycodone vs. morphine for the treatment of chronic low back pain: results of a 12 week prospective, randomized, open-label blinded endpoint streamlined study with prolonged-release preparations. Curr Med Res Opin. 2015;31(7):1413-1429.

58. Webster LR, Brenner DM, Barrett AC, Paterson C, Bortey E, Forbes WP. Analysis of opioid-mediated analgesia in phase III studies of methylnaltrexone for opioid-induced constipation in patients with chronic noncancer pain. J Pain Res. 2015;8:771-780.

59. Morlion B, Clemens KE, Dunlop W. Quality of life and healthcare resource in patients receiving opioids for chronic pain: a review of the place of oxycodone/naloxone. Clin Drug Investig. 2015;35(1): $1-11$.

60. Mercadante S, Giarratano A. Combined oral prolonged-release oxycodone and naloxone in chronic pain management. Expert Opin Investig Drugs. 2013;22(1):161-166.

61. Holzer P. Non-analgesic effects of opioids: management of opioid-induced constipation by peripheral opioid receptor antagonists: prevention or withdrawal? Curr Pharm Des. 2012;18(37):6010-6020.

62. FDA [webpage on the Internet]. Entereg (alvimopan) capsules. MedWatch The FDA Safety Information and Adverse Event Reporting Program. 2013. Available from: http://www.fda.gov/Safety/MedWatch/ SafetyInformation/ucm194328.htm. Accessed January 27, 2016.
63. Webster L, Chey WD, Tack J, Lappalainen J, Diva U, Sostek M. Randomised clinical trial: the long-term safety and tolerability of naloxegol in patients with pain and opioid-induced constipation. Aliment Pharmacol Ther. 2014;40(7):771-779.

64. Webster L, Dhar S, Eldon M, Masuoka L, Lappalainen J, Sostek M. A phase 2, double-blind, randomized, placebo-controlled, dose-escalation study to evaluate the efficacy, safety, and tolerability of naloxegol in patients with opioid-induced constipation. Pain. 2013;154(9):1542-1550.

65. Zhang Y, Williams DA, Zaidi SA, et al. 17-Cyclopropylmethyl-3,14 $\beta$ dihydroxy-4,5 $\alpha$-epoxy-6 $\beta$-(4'-pyridylcarboxamido)morphinan (NAP) modulating the $\mathrm{Mu}$ opioid receptor in a biased fashion. ACS Chem Neurosci. 2016;7(3):297-304.

66. Trinkley KE, Sill BE, Porter K, Nahata MC. Prescribing patterns for outpatient treatment of constipation, irritable bowel syndromerelated constipation, and opioid-induced constipation: a retrospective cross-sectional study. J Manag Care Spec Pharm. 2015;21(11): 1077-1087.

67. Wan Y, Corman S, Gao X, Liu S, Patel H, Mody R. Economic burden of opioid-induced constipation among long-term opioid users with noncancer pain. Am Health Drug Benefits. 2015;8(2):93-102.

68. Dunlop W, Uhl R, Khan I, Taylor A, Barton G. Quality of life benefits and cost impact of prolonged release oxycodone/naloxone versus prolonged release oxycodone in patients with moderate-to-severe non-malignant pain and opioid-induced constipation: a UK cost-utility analysis. J Med Econ. 2012;15(3):564-575.

69. Goeree R, Goeree J. Cost-effectiveness analysis of oxycodone with naloxone versus oxycodone alone for the management of moderateto-severe pain in patients with opioid-induced constipation in Canada J Med Econ. 2015;30:1-15.
Patient Preference and Adherence

\section{Publish your work in this journal}

Patient Preference and Adherence is an international, peer-reviewed, open access journal that focuses on the growing importance of patient preference and adherence throughout the therapeutic continuum. Patient satisfaction, acceptability, quality of life, compliance, persistence and their role in developing new therapeutic modalities and compounds to optimize

\section{Dovepress}

clinical outcomes for existing disease states are major areas of interest for the journal. This journal has been accepted for indexing on PubMed Central. The manuscript management system is completely online and includes a very quick and fair peer-review system, which is all easy to use. Visit http://www. dovepress.com/testimonials.php to read real quotes from published authors. 